\title{
Directions for High-Temperature Shape Memory Alloys' Improvement: Straight Way to High-Entropy Materials?
}

\author{
G. S. Firstov ${ }^{1}$ T. A. Kosorukova ${ }^{1} \cdot$ Yu N. Koval $^{1} \cdot$ P. A. Verhovlyuk ${ }^{1}$
}

Published online: 30 October 2015

(c) ASM International 2015

\begin{abstract}
Nowadays, all thermo-mechanical effects, associated with the martensitic structural phase transitions, are still in the focus of scientists and engineers, especially once these phenomena are taking place at elevated temperatures. The list of the materials, undergoing high-temperature martensitic transformation, is constantly widening. Still, industrial application of these materials, called hightemperature shape memory alloys, is far enough due to the lack of understanding of the peculiarities of the high-temperature martensitic transformation and shape memory effect. The present work attempts to show how the development of the proper directions for high-temperature shape memory alloys' improvement might lead to the creation of essentially new functional materials.
\end{abstract}

Keywords Martensitic phase transformation - Crystal and electronic structure - Shape memory behaviour . High temperature shape memory alloys · High entropy alloys

This article is an invited paper selected from presentations at the International Conference on High-Temperature Shape Memory Alloys 2015, held May 5-8 2015, in Wildbad Kreuth Educational Centre in Kreuth, Bavaria, Germany, and has been expanded from the original presentation.

G. S. Firstov

gfirst@imp.kiev.ua; yuri.firstov@gmail.com

1 G.V. Kurdyumov Institute for Metal Physics of the National Academy of Sciences of Ukraine, 36 Vernadsky blvd., Kiev 03680, Ukraine

\section{Introduction}

There is quite a number of reviews and monographs (see [1] or [2] for example) dedicated to the description of shape memory effect (SME) and related phenomena published over the years since the discovery by Buehler, Gilfrich and Wiley [3] of the SME in TiNi intermetallic compound. Generally, they are focused on the two types of shape memory alloys, TiNi- [4] and Cu-based [5], as they have been successfully applied in industry due to the thermoelastic origin of the martensitic transformation (MT), taking place in these materials. Thermoelastic phase equilibrium phenomenon, discovered by Kurdyumov and Khandros in $\mathrm{Cu}-\mathrm{Al}-\mathrm{Ni}$ alloy [6], ensures the structural reversibility during forward $\leftrightarrow$ reverse MT due to the coherency at the austenite/martensite interface. Such coherency results in the rising of the internal stresses during the martensite crystal formation that lead to elastic contribution to the energy balance at MT and, as a result, to reversible appearance-disappearance of "elastic" martensite crystals on cooling-heating through the MT interval, noticed in [6]. Application of the external stresses to alloys, undergoing thermoelastic MT, results in a macroscopic reversibility during shape change at shape memory or superelastic behaviour. Yet, even if the TiNi- or $\mathrm{Cu}$-based shape memory alloys show all signs of thermoelastic behaviour, certain degree of the plastic relaxation (creation and movement of full dislocations) of the internal stresses at austenite/martensite interface might not be avoided. Subsequently, thermal cycling effects (or thermal fatigue) appear $[7,8]$, as well as the degradation of shape memory effect [9] and mechanical [8], functional or structural [10] fatigue phenomena. Obviously, all these irreversible processes intensify at elevated temperatures, as it might be seen, for example, in the case of $\mathrm{Ti}_{50} \mathrm{Pd}_{40} \mathrm{Ni}_{10}$ high- 
temperature shape memory alloy [11] because of the irreversible plastic flow in a first place or structural fatigue $(\omega$ phase formation), likewise it can be seen in Ti-Ta during diffusive phase transformation [10]. All of them become the obstacles for successful application of high-temperature shape memory alloys (HTSMAs) $[12,13]$.

In spite of considerable amount of HTSMA data accumulated over the years, the systematic HTSMA study was not undertaken; all research efforts were split amongst individual HTSMA systems [12, 13]. In the previous work [14], an attempt was made to develop certain physical principles suitable for HTSMA design. The aim of the present paper is to show how the use of such principles leads to the development of the novel class of functional materials-high-entropy shape memory alloys, which were discovered very recently [15].

\section{Experimental}

$\mathrm{Ti}-\mathrm{Zr}-\mathrm{Hf}-\mathrm{Co}-\mathrm{Ni}-\mathrm{Cu}$ alloys studied were arc-melted from iodide $\mathrm{Ti}, \mathrm{Zr}$ and $\mathrm{Hf}$ and electrolytic $\mathrm{Co}, \mathrm{Ni}$ and $\mathrm{Cu}$ in a pregettered argon atmosphere and poured into a watercooled copper mould. The weight of the ingots was typically $15-25 \mathrm{~g}$. MT temperatures were detected with the help of Netzsch $404 \mathrm{~F} 1$ differential scanning calorimeter using a heating-cooling rate of $10 \mathrm{~K} / \mathrm{min}$. Shape memory behaviour was studied in three-point bending under the static load in $77-1100 \mathrm{~K}$ temperature range. Hardness and elastic modulus at room temperature were measured using instrumented indentation test for hardness (ISO 14577-1:2002(E)) with the help of "Micron-Gamma" device equipped with Berkovich indenter.

\section{Results and Discussion}

First of all, let us consider the directions for HTSMA improvement based upon the physical principles developed in [14]. In general, materials possessing high melting temperatures $\left(T_{\text {melt }}\right)$ and relatively high MT temperatures (above $0.3 T_{\text {melt }}$ ) are quite promising for SME at elevated temperatures. These materials are intermetallic compounds that undergo MT from B2 austenite into low symmetry martensitic phase, and for them the processes of the plastic relaxation of arising internal stresses are suppressed. Especially attractive are those intermetallics that possess the symmetry of high-temperature austenitic phase lower than cubic, like in the case of $\mathrm{Ni}_{3} \mathrm{Ta}$ intermetallic compound [16] with high-temperature phase structure belonging to tetragonal syngony. In this case, the basic planes for martensite do not coincide with easy gliding planes for dislocations in austenite, which prevents irreversible plastic deformation. Amongst the group of materials with hightemperature shape memory, alloy systems with inexpensive constituents like $(\mathrm{Cu}, \mathrm{Ni}, \mathrm{Co})-(\mathrm{Ti}, \mathrm{Zr})$ and $\mathrm{Ni}_{3} \mathrm{Ta}$ in its homogeneity range attract special attention. For them, the temperature interval of high-temperature shape recovery is in 400-900 K temperature range.

It should be fairly noted that the absolute values of shape recovery temperatures are less important than the ratio of the starting temperature of the reverse MT $\left(A_{\mathrm{s}}\right)$ to melting temperature as plastic flow and diffusive processes, including thermal, mechanical, functional and structural fatigue, mentioned in the introduction, intensify above $A_{\mathrm{s}} l$ $T_{\text {melt }} \approx 0.5$. It can be seen, when one considers candidates among intermetallics for the so-called ultra-high-temperature shape recovery. Analysis of phase diagrams with $\mathrm{AB}$ binary compounds (A-Ti, $\mathrm{Zr}, \mathrm{Hf}, \mathrm{Nb}, \mathrm{Ta} ; \mathrm{B}-\mathrm{Co}, \mathrm{Ni}, \mathrm{Cu}$, $\mathrm{Ru}, \mathrm{Rh}, \mathrm{Pd}, \mathrm{Ir}, \mathrm{Pt}, \mathrm{Au}$ ) has shown that in some of these intermetallics MT at relatively high temperatures was already detected or might be deduced from the information available [17-26]. $A_{\mathrm{s}}, T_{\text {melt }}, A_{\mathrm{s}} / T_{\text {melt }}$ ratio and shape recovery ratio $\left(K_{\mathrm{SME}}\right)$ for these intermetallics are shown in Table 1.

It is visible (Table 1) that $A_{\mathrm{s}}$ temperature might be chosen from 800 to $1860 \mathrm{~K}$ and for most studied intermetallics [18-26] MT was reported as quite reversible and even thermoelastic similar to TiNi and CuAlNi. While TiNi and CuAlNi exhibit complete shape recovery, the candidates for ultra-high-temperature shape recovery performed poorly except for two intermetallics: $\mathrm{ZrRh}$ and $\mathrm{HfIr}$ (Table 1, bold). The reason is that for $\mathrm{ZrRh}, A_{\mathrm{s}} l$ $T_{\text {melt }}=0.39$, while for HfIr it is even smaller-0.36, which is almost the same as for CuAlNi industrial shape memory alloy. $A_{\mathrm{s}} / T_{\text {melt }}$ ratio is well below 0.5 for TiNi, CuAlNi, $\mathrm{ZrRh}$ and HfIr, indicating that diffusive and plastic processes are frozen well enough. That is why HfIr shows the complete recovery of about $1 \%$ of accumulated strain in the $1000-1300 \mathrm{~K}$ temperature range [24]. On the other hand, for $\mathrm{HfNi}\left(A_{\mathrm{s}}=1400 \mathrm{~K}\right)$, where temperature-induced MT shows all signs of thermoelasticity, the shape recovery does not happen at all because $A_{\mathrm{s}} / T_{\text {melt }}=0.78$, indicating that diffusive and plastic flow processes already lead to complete loss of coherency on the austenite/martensite interface through internal stress relaxation. The same is very true for $\mathrm{HfPd}\left(K_{\mathrm{SME}}=5.8 \%\right)$ [21] and $\mathrm{TiPt}$ $\left(K_{\mathrm{SME}}=7.5 \%\right)$ [26] intermetallics. It can be also seen that in general the decrease of $A_{\mathrm{s}} / T_{\text {melt }}$ leads to the increase in shape recovery although if this ratio is above 0.4 the shape recovery is incomplete.

According to [12-14], existing HTSMA drawbacks are poor mechanical properties that lead to unacceptable machinability, insufficient recoverable deformations and the fact that these recoverable deformations are accompanied by irreversible plastic ones. To overcome 
Table $1 A_{\mathrm{s}}, T_{\text {melt }}, A_{\mathrm{s}} / T_{\text {melt }}$ ratio and shape recovery ratio $\left(K_{\mathrm{SME}}=\varepsilon_{\mathrm{R}} / \varepsilon_{\mathrm{M}} \times 100 \%\right.$, where $\varepsilon_{\mathrm{M}}$ is the accumulated strain and $\varepsilon_{\mathrm{R}}$ is the recovered strain) of intermetallic candidates for ultra-hightemperature shape recovery and TiNi and CuAlNi classic shape memory alloys given for comparison

\begin{tabular}{|c|c|c|c|c|c|}
\hline Intermetallic & $A_{\mathrm{S}}(\mathrm{K})$ & $T_{\text {melt }}(\mathrm{K})$ & $A_{\mathrm{S}} / T_{\text {melt }}$ & $K_{\mathrm{SME}}(\%)$ & Reference \\
\hline TiAu & 800 & 1770 & 0.45 & $55-78$ & {$[17,18,21]$} \\
\hline $\mathrm{ZrAu}$ & 840 & 1848 & 0.45 & - & [17] \\
\hline ZrRh & 840 & 2180 & 0.39 & 100 & [19] \\
\hline TiPd & 850 & 1670 & 0.51 & 60 & {$[17,20]$} \\
\hline HfPd & 930 & 1880 & 0.49 & 5.8 & {$[17,21]$} \\
\hline $\mathrm{Zr}_{50} \mathrm{Cu}_{25} \mathrm{Ni}_{25}$ & 960 & 1370 & 0.70 & 90 & {$[17,22]$} \\
\hline $\mathrm{Zr}_{50} \mathrm{Co}_{25} \mathrm{Ni}_{25}$ & 970 & 1510 & 0.64 & 90 & {$[17,23]$} \\
\hline HfIr & 970 & 2700 & 0.36 & 100 & {$[17,24]$} \\
\hline $\mathrm{ZrPd}$ & 1040 & 1870 & 0.56 & - & {$[17]$} \\
\hline HfAu & 1070 & 1690 & 0.63 & - & {$[17]$} \\
\hline $\mathrm{NbRu}$ & 1150 & 2215 & 0.52 & 50 & {$[17,25]$} \\
\hline ZrIr & 1150 & 2320 & 0.49 & 75 & [19] \\
\hline TiIr & 1300 & 2400 & 0.54 & - & [17] \\
\hline TiPt & 1320 & 2130 & 0.62 & 7.5 & {$[17,26]$} \\
\hline TaRu & 1370 & 2320 & 0.59 & 50 & {$[17,25]$} \\
\hline $\mathrm{Ti}_{50} \mathrm{Pt}_{25} \mathrm{Ir}_{25}$ & 1400 & 2270 & 0.62 & 45 & {$[17,26]$} \\
\hline $\mathrm{HfNi}$ & 1400 & 1795 & 0.78 & 0 & [19] \\
\hline TiRh & 1550 & 2210 & 0.70 & - & [17] \\
\hline $\mathrm{ZrPt}$ & 1860 & 2270 & 0.82 & - & [17] \\
\hline TiNi & 350 & 1580 & 0.22 & 100 & {$[4,17]$} \\
\hline $\mathrm{CuAlNi}$ & 470 & 1320 & 0.35 & 100 & {$[5,17]$} \\
\hline
\end{tabular}

these difficulties, one might use the path of HTSMA production via amorphous state [27] to obtain chemically homogeneous material or/and increase martensitic deformation through structure refinement [28]. The accumulation of the irreversible plastic deformation during SME, which becomes easier in HTSMA due to the coincidence of the easy gliding planes for dislocations in austenite and basic planes of martensite, can be avoided with the help of complication of MT crystallography through the symmetry decrease of the austenitic phase [16], solid solution hardening, ageing [29], creation of natural shape memory composites [23] and also by suppression of the diffusion processes of relaxation of internal stresses, which can be ensured through the increase of HTSMA melting temperatures and minimization of $A_{\mathrm{s}} / T_{\text {melt }}$ ratio [14]. It should be also noted that mutual use of the directions for HTSMA improvement is rather difficult, although such an attempt was made already for $\mathrm{ZrCu}$-based HTSMA through $\mathrm{Ni}$, Co and $\mathrm{Ti}$ alloying additions [30, 31]. This five-component HTSMA was the best among $\mathrm{ZrCu}$-based family although the saturation of the positive influence on shape memory characteristics was noticed.

On the other hand, once the race for HTSMA kept going for the last 15 years, almost at the same time, Yeh and coauthors produced an impressive breakthrough in structural materials' design by proposing entirely new concept of high-entropy alloys (HEAs) [32]. This concept involves the creation of the multi-element metallic materials close to equimolar composition (without the principal element) with the entropy of mixing higher comparing to the existing materials and ensuring in such way high phase stability $[33,34]$. HEAs can be obtained as solid solutions, bulk metallic glasses and even intermetallic compounds, some of them being reported to possess B2 type of structure [35] to which the structure of the NiTi shape memory alloy austenite belongs. It was shown already that HEAs possess unusually high hardness due to the non-obvious solid solution hardening [36] and diffusion in these materials is sluggish [37]. These HEA properties were those that existing HTSMA needed for improvement, including multi-component $\mathrm{ZrCu}$-based HTSMA [30, 31].

Very recently, following HEA concept mentioned above, it was found that one $\mathrm{Ti}_{16.667} \mathrm{Zr}_{16.667} \mathrm{Hf}_{16.667} \mathrm{Ni}_{25}$ $\mathrm{Cu}_{25}$ HEA of TiZrHfCoNiCu intermetallic family undergoes $\mathrm{B} 2 \leftrightarrow \mathrm{B} 19$ ' martensitic transformation (MT), which is accompanied by shape memory effect with attractive parameters [15], including MT and shape memory temperatures above $400 \mathrm{~K}$ that indeed make it HTSMA a good candidate. Below, further studies of MT and SME in TiZrHfCoNiCu high-entropy intermetallic family will be presented.

As it was clear from the results of [15], Co in equiatomic TiZrHfCoNiCu intermetallic completely stabilized hightemperature austenite $\mathrm{B} 2$ phase. So, MT ought to be found somewhere between $\mathrm{Ti}_{16.667} \mathrm{Zr}_{16.667} \mathrm{Hf}_{16.667} \mathrm{Ni}_{25} \mathrm{Cu}_{25}$ and $\mathrm{Ti}_{16.667} \mathrm{Zr}_{16.667} \mathrm{Hf}_{16.667} \mathrm{Co}_{16.667} \mathrm{Ni}_{16.667} \mathrm{Cu}_{16.667}$ 
compositions. To do that, (TiZrHf $)_{50}(\mathrm{CoNiCu})_{50}$ alloys were prepared, containing different amounts of $\mathrm{Co}, \mathrm{Ni}$ and $\mathrm{Cu}$ ( $\mathrm{Ti}, \mathrm{Zr}$ and $\mathrm{Hf}$ in equal amounts-16.667 at.\%). It should be also noted that all HEAs were studied in the ascast state. Dendritic segregation was found in all of them by scanning electron microscopy. Broad description of this study will be published elsewhere. Here we will use its results for $\mathrm{Ti}_{16.667} \mathrm{Zr}_{16.667} \mathrm{Hf}_{16.667} \mathrm{Ni}_{25} \mathrm{Cu}_{25}$ intermetallic, where compositions for dendrites and interdendritic space were determined and arc-melted as a separate $\mathrm{Ti}_{14.53} \mathrm{Zr}_{14.26} \mathrm{Hf}_{21.17} \mathrm{Ni}_{30.15} \mathrm{Cu}_{19.89}$ and $\mathrm{Ti}_{18.15} \mathrm{Zr}_{18.75} \mathrm{Hf}_{14.33}$ $\mathrm{Ni}_{21.64} \mathrm{Cu}_{27.13}$ alloys. The results of DSC and SME measurements for all these alloys underwent MT are shown in Table 2.

It is visible (Table 2) that Ms temperature varies in the wide temperature range from 260 to $675 \mathrm{~K}$. Co additions indeed strongly suppress MT. The strongest is the effect of $\mathrm{Ni}$ substitution by $\mathrm{Co}$, as the rate of Ms decrease is $-25 \mathrm{~K} /$ at.\% of Co. The effect of $\mathrm{Cu}$ substitution is much less pronounced (rate of Ms decrease is $-7 \mathrm{~K} / \mathrm{at} . \%$ of $\mathrm{Co}$ ), while mutual substitution of $\mathrm{Ni}$ and $\mathrm{Cu}$ by $\mathrm{Co}$ is almost the same for $\mathrm{Ni}$ substitution only-rate of Ms decrease is $-24 \mathrm{~K} /$ at. $\%$ of Co. As for dendrite and interdendritic $\mathrm{Ti}_{14.53} \mathrm{Zr}_{14.26} \mathrm{Hf}_{21.17} \mathrm{Ni}_{30.15} \mathrm{Cu}_{19.89}$ and $\mathrm{Ti}_{18.15} \mathrm{Zr}_{18.75} \mathrm{Hf}_{14.33}$ $\mathrm{Ni}_{21.64} \mathrm{Cu}_{27.13}$ compositions, it is clear that in the first (dendritic) composition an increase in $\mathrm{Hf}$ and $\mathrm{Ni}$ content is observed, which resulted in the highest Ms amongst considered alloys. The second (interdendritic) composition is characterised by the increase in $\mathrm{Ti}, \mathrm{Zr}$ and $\mathrm{Cu}$ content, while Ms is still just above $400 \mathrm{~K}$ (Table 2). These effects are definitely related to interatomic interaction specific for HEA in question and will need further structural experimental and modelling studies.

Still, the most attractive amongst all HEAs in question is $\mathrm{Ti}_{16.667} \mathrm{Zr}_{16.667} \mathrm{Hf}_{16.667} \mathrm{Co}_{10} \mathrm{Ni}_{25} \mathrm{Cu}_{15}$, as it exhibits high values of MT heats (implying that most of the material is taking part in MT), narrow MT hysteresis (Fig. 1) and the highest value of martensitic strain in HTSMA temperature range (Table 2) that was recovered completely (Fig. 2).

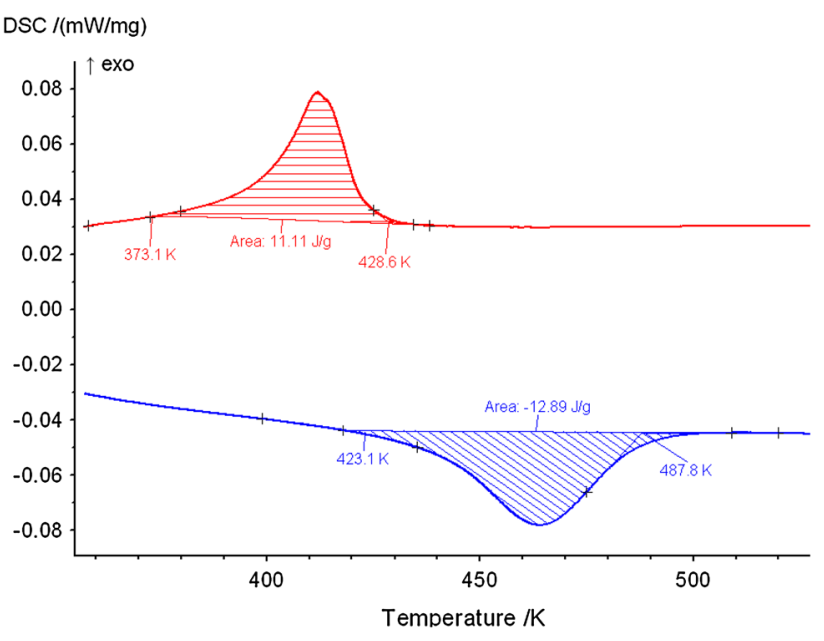

Fig. 1 DSC measurements of the complete MT cycle for $\mathrm{Ti}_{16.667}$ $\mathrm{Zr}_{16.667} \mathrm{Hf}_{16.667} \mathrm{Co}_{10} \mathrm{Ni}_{25} \mathrm{Cu}_{15}$ high-entropy intermetallic

DSC measurements of the complete MT cycle for this high-entropy intermetallic (Fig. 1) show also that not only the hysteresis is narrow $(\Delta T=55 \mathrm{~K})$ but the temperature intervals of MT are also narrow (50-60 K), comparing with wide $\Delta T=92 \mathrm{~K}$ and $\mathrm{MT}$ intervals for $\mathrm{Ti}_{16.667}$ $\mathrm{Zr}_{16.667} \mathrm{Hf}_{16.667} \mathrm{Ni}_{25} \mathrm{Cu}_{25}$ ([38], Table 2). This kind of behaviour during MT in $\mathrm{Ti}_{16.667} \mathrm{Zr}_{16.667} \mathrm{Hf}_{16.667} \mathrm{Co}_{10} \mathrm{Ni}_{25}$ $\mathrm{Cu}_{15}$ is quite close to thermoelastic one. It is indirectly confirmed during SME measurements in three-point bending shown in Fig. 2.

After heating over $800 \mathrm{~K}$, the plate-like specimen was loaded in three-point bending. The load induced $500 \mathrm{MPa}$ in surface layers in the upper and bottom sides of the specimen. Load-unload at this temperature confirmed that no plastic flow occurred. Then, the specimen was cooled under the static load and already at $700 \mathrm{~K}$ the strain additional to elastic one started to occur. Further cooling registered more intensive bending below $420 \mathrm{~K}$, which corresponds to Ms of the stress-free MT measured in DSC (Fig. 1; Table 2). Accumulation of the martensitic strain of
Table 2 Composition of TiZrHfCoNiCu high-entropy intermetallics, their MT temperatures (Ms, Mf, As, Af) and heats $\left(Q^{M-A}\right.$-released upon forward MT on cooling; $Q^{A-M}$ _absorbed upon reverse MT on heating)

\begin{tabular}{lllllllllllllll}
\hline $\begin{array}{l}\mathrm{Ti} \\
\text { at.\% }\end{array}$ & $\mathrm{Zr}$ & $\mathrm{Hf}$ & $\mathrm{Co}$ & $\mathrm{Ni}$ & $\mathrm{Cu}$ & $\mathrm{Ms}$ & $\mathrm{Mf}$ & $\mathrm{As}$ & Af & $\Delta T$ & $\begin{array}{l}Q^{M-A} \\
\mathrm{~K}\end{array}$ & $Q^{M-A}$ & $\mathrm{Ed}$ & $\begin{array}{l}\varepsilon_{\mathrm{R}} \\
\%\end{array}$ \\
\hline 14.53 & 14.26 & 21.17 & - & 30.15 & 19.89 & 675 & 482 & 659 & 911 & 206 & 20.08 & 22.42 & 2.34 & 0.6 \\
16.67 & 16.67 & 16.67 & - & 25 & 25 & 500 & 385 & 458 & 611 & 92 & 3.47 & 5.248 & 1.78 & 0.4 \\
16.67 & 16.67 & 16.67 & 5 & 25 & 20 & 454 & 405 & 462 & 532 & 68 & 10.3 & 11.28 & 0.98 & 1.16 \\
16.67 & 16.67 & 16.67 & 10 & 25 & 15 & 430 & 373 & 423 & 488 & 55 & 11.11 & 12.89 & 1.78 & 1.63 \\
18.15 & 18.75 & 14.33 & - & 21.64 & 27.13 & 414 & 339 & 354 & 520 & 60 & 9.75 & 11.19 & 1.44 & 0.55 \\
16.67 & 16.67 & 16.67 & 5 & 20 & 25 & 376 & 259 & 319 & 451 & 68 & 8.678 & 9.797 & 1.12 & 1.19 \\
16.67 & 16.67 & 16.67 & 10 & 20 & 20 & 263 & 200 & 240 & 317 & 47 & 6.623 & 7.152 & 0.53 & 1.84 \\
\hline
\end{tabular}

$\Delta T=\left(A_{\mathrm{S}}+\left(A_{\mathrm{F}}-A_{\mathrm{S}}\right) / 2\right)-\left(M_{\mathrm{F}}+\left(M_{\mathrm{S}}-M_{\mathrm{F}}\right) / 2\right)$

MT thermal hysteresis, $\Delta T$ energy lost in a complete MT cycle $E d=Q^{A-M}-Q^{M-A}$, according to [38], and strain recovered in three-point bending experiments $\left(\varepsilon_{\mathrm{R}}\right)$ are also shown 


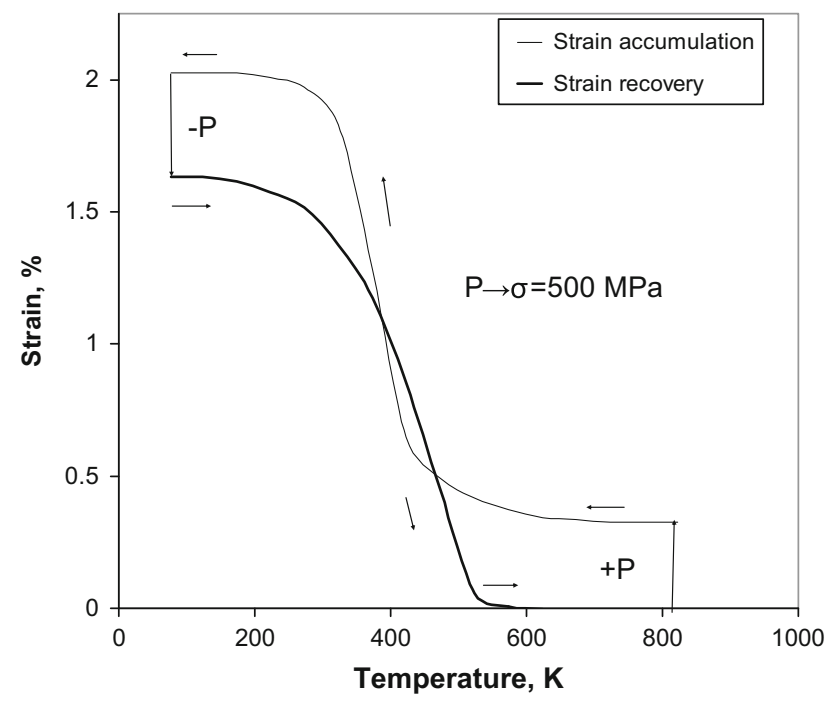

Fig. 2 SME measurements of the complete MT cycle for $\mathrm{Ti}_{16.667}$ $\mathrm{Zr}_{16.667} \mathrm{Hf}_{16.667} \mathrm{Co}_{10} \mathrm{Ni}_{25} \mathrm{Cu}_{15}$ high-entropy intermetallic in three-point bending. Arrows indicate cooling and subsequent heating as well as application or removal of external load $( \pm P)$ that resulted in the stress of $500 \mathrm{MPa}$

$1.6 \%$ on cooling under $500 \mathrm{MPa}$ finished just above $300 \mathrm{~K}$, which also corresponds with the DSC data (Fig. 1; Table 2) well enough. After cooling to liquid nitrogen temperature, the specimen was unloaded and heated up to $600 \mathrm{~K}$. At temperatures about $200 \mathrm{~K}$, shape recovery already started but the most intensive shape recovery process began at around $300 \mathrm{~K}$ and was finished just above $500 \mathrm{~K}$. Complete shape recovery has been taking place not only for $\mathrm{Ti}_{16.667} \mathrm{Zr}_{16.667} \mathrm{Hf}_{16.667} \mathrm{Co}_{10} \mathrm{Ni}_{25} \mathrm{Cu}_{15}$ intermetallic shown in Fig. 2 but for all HEAs in Table 2. Only recovered strain accumulated at $500 \mathrm{MPa}$ varies (Table 2). The reason for this is related to crystal structure parameter changes in austenitic B2 and martensitic B19' phases, which are described in [39]. Here we shall use only relative volume change during forward MT calculated from volume per atom values for martensite and austenite, which are calculated in their own turn from lattice parameters, taking into account the number of atoms in the unit cell. So, Fig. 3 represents relative volume change during forward MT, recovered strain and MT hysteresis depending upon Ms temperature for all HEAs from Table 2.

It can be seen (Fig. 3) that for most of the HEAs the volume change is quite significant and has a positive sign (martensite has bigger specific volume comparing to austenite). Yet, in the case of the most attractive in a sense of HTSMA parameters $\mathrm{Ti}_{16.667} \mathrm{Zr}_{16.667} \mathrm{Hf}_{16.667} \mathrm{Co}_{10} \mathrm{Ni}_{25}$ $\mathrm{Cu}_{15}$ intermetallic, the volume change undergoes a minimum at $\mathrm{Ms}$ dependence $(\mathrm{Ms}=430 \mathrm{~K})$. Moreover, it changes sign from positive to negative and its absolute value is the smallest one. It means that $\mathrm{MT}$ in $\mathrm{Ti}_{16.667}$ $\mathrm{Zr}_{16.667} \mathrm{Hf}_{16.667} \mathrm{Co}_{10} \mathrm{Ni}_{25} \mathrm{Cu}_{15}$ intermetallic shows all signs

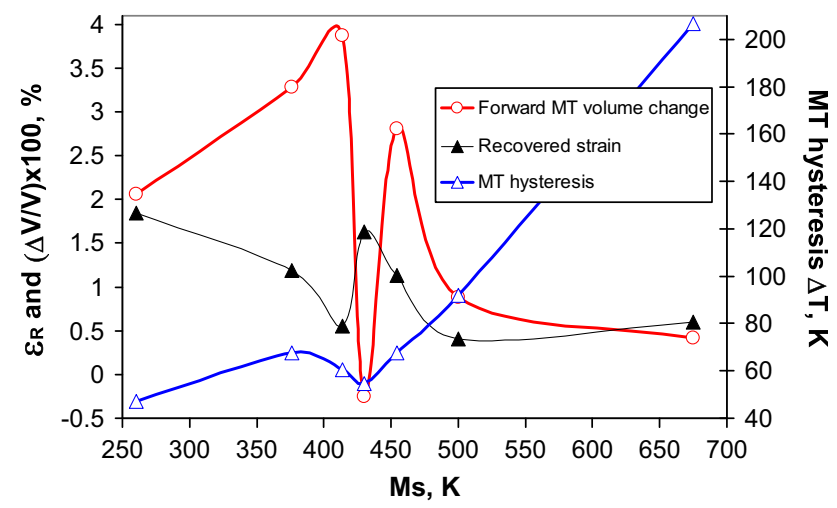

Fig. 3 Forward MT relative volume change $(\Delta V / V)$, recovered strain $\varepsilon_{\mathrm{R}}$ and MT hysteresis depending upon Ms for HEAs studied in the present work (Table 2)

of thermoelastic behaviour similar to TiNi, which has negative sign for the volume change also, and contrary to HTSMAs that exhibit positive sign of the volume change [14]. That is the reason why MT hysteresis that represents the degree of irreversible processes shows minimum that coincides with the minimum in volume change. It is no surprise that recovered strain exhibits maximum that coincides with the minima mentioned above (Fig. 3). As for the fact that despite quite high external stresses (500 $\mathrm{MPa})$ applied at elevated temperatures, there is complete shape recovery for all HEAs in question, one should take into account their mechanical properties. It was expected to see significant solution hardening mentioned above [36], although this hardening was observed for solid solutions only. In our case, we are dealing with high-entropy intermetallics, which could behave differently. In the present work, hardness $\left(H_{\text {Meyer }}\right)$ was measured simultaneously with elastic modulus by means of instrumented indentation test for hardness (ISO 14577-1:2002(E)) with the help of "Micron-Gamma" device equipped with Berkovich indenter. The results depending upon Ms for all HEAs in question are shown in Fig. 4.

It should be noted that absolute hardness values are higher for HEAs, comparing with $\mathrm{TiNi}$, which we measured also and obtained $H_{\text {Meyer }}=6 \mathrm{GPa}$ for it. In general, hardness increases from 9 to $12 \mathrm{GPa}$ with $\mathrm{Ms}$ increase. So, solution hardening takes place indeed and that is the reason for complete shape recovery for all HEAs studied in the present work. Still, hardness produces a minimum together with elastic modulus (Fig. 4) that corresponds to the minima in volume change and hysteresis (Fig. 3), and hardness becomes close in value to TiNi for $\mathrm{Ti}_{16.667} \mathrm{Zr}_{16.667} \mathrm{Hf}_{16.667}$ $\mathrm{Co}_{10} \mathrm{Ni}_{25} \mathrm{Cu}_{15}$ high-entropy intermetallic. In the case of TiNi, during the hardness measurements, the formation of stress-induced martensite and reorientation of existing one take place under the indenter due to high mobility of the 


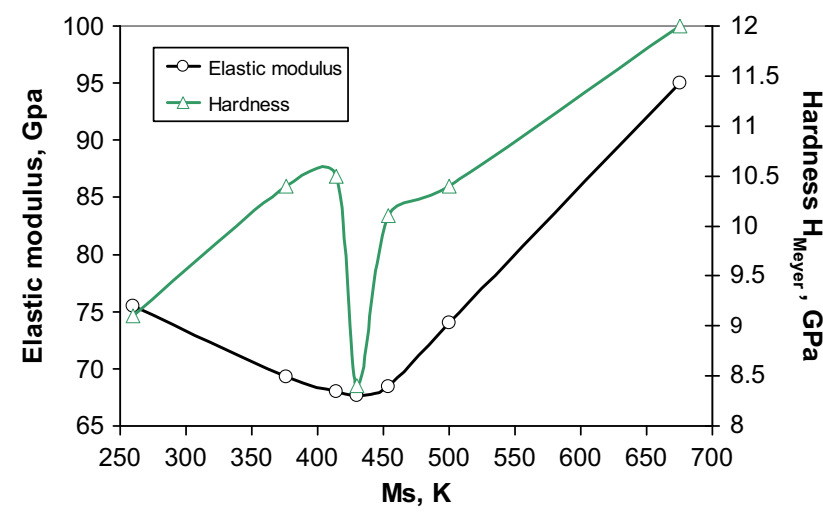

Fig. 4 Elastic modulus and hardness $\left(H_{\text {Meyer }}\right)$ dependences upon Ms for HEAs studied in the present work (Table 2)

austenite/martensite and martensite/martensite interfaces. Most probably, the same takes place in $\mathrm{Ti}_{16.667} \mathrm{Zr}_{16.667}$ $\mathrm{Hf}_{16.667} \mathrm{Co}_{10} \mathrm{Ni}_{25} \mathrm{Cu}_{15}$ and a strong drop in hardness is observed as a result. The reason for such high interface mobility and general lattice softening (minimum in elastic modulus in Fig. 4) is definitely related to crystal structure peculiarities of the austenite and martensite, including substructural ones, which would need additional extensive studies.

Finally, let us consider relative position of the studied high-entropy shape memory alloys (Table 2) among binary intermetallic compounds like classic shape memory alloy TiNi [4, 17], HTSMA ZrCu [17, 40], B33 stable $\mathrm{ZrNi}$ [17] and equimolar TiZrHfNiCu, TiZrHfCoCu [41] amorphous HEAs, using parameters to characterise the collective behaviour of the constituent elements in the multi-component HEA: the atomic size difference $(\delta)$, the mixing enthalpy $\left(\Delta H_{\text {mix }}\right)$, the mixing entropy $\left(\Delta S_{\text {mix }}\right)$ and the valence electron concentration (VEC) according to [35] together with $\Omega$ parameter $\left(\Omega=\frac{T_{\text {melt }} \Delta S_{\text {mix }}}{\left|\Delta H_{\text {mix }}\right|}\right)$ proposed in [42]. The results of such consideration are shown in Figs. 5 and 6.

Figure 5 shows mixing entropy $\left(\Delta S_{\text {mix }}\right)$ depending upon valence electron concentration (VEC). It can be seen that mixing entropy of TiZrHfCoNiCu intermetallics is indeed in the high entropy range between 13.196 and $14.897 \mathrm{Jmol}^{-1}$ $\mathrm{K}^{-1}$; these values are much higher, comparing with binary intermetallic compounds shown in Fig. 5. TiZrHfCoNiCu intermetallics with a stable B2 structure (data taken from [15, 39]) have $\Delta S_{\text {mix }}=13.211 \mathrm{Jmol}^{-1} \mathrm{~K}^{-1}$, which is slightly smaller than the value for amorphous HEA$13.381 \mathrm{Jmol}^{-1} \mathrm{~K}^{-1}$, while most of the TiZrHfCoNiCu intermetallics that undergo B2 $\leftrightarrow \mathrm{B} 19^{\prime}$ MT have significantly higher $\Delta S_{\text {mix }}$ in the range of $14.252-14.897 \mathrm{Jmol}^{-1} \mathrm{~K}^{-1}$. Obviously, a rise in the mixing entropy might stabilize the forming phases only to diffusion transformations, while diffusionless structural instability is quite possible. It should be also noted that TiZrHfCoNiCu intermetallics undergoing MT

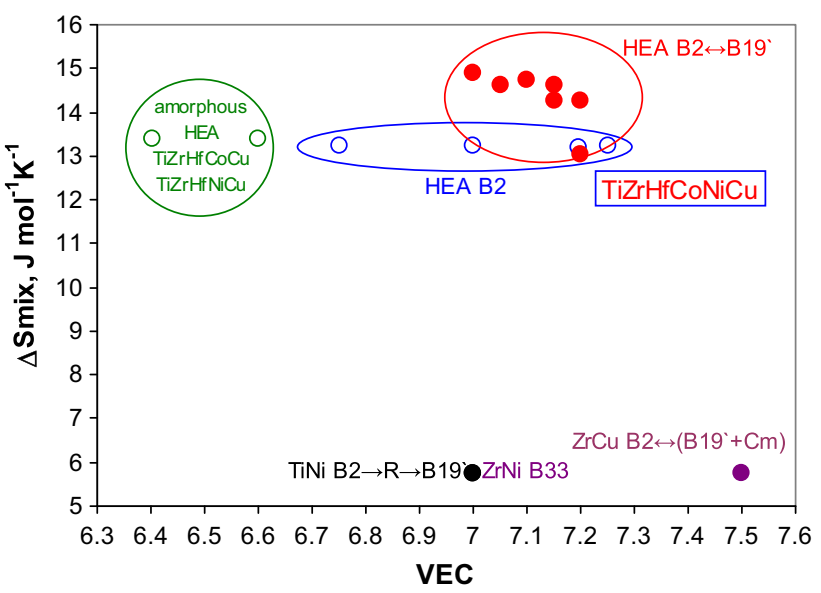

Fig. 5 Mixing entropy $\left(\Delta S_{\text {mix }}\right)$ dependence upon valence electron concentration (VEC) for TiZrHfCoNiCu high-entropy intermetallics and some amorphous HEAs and binary intermetallic compounds

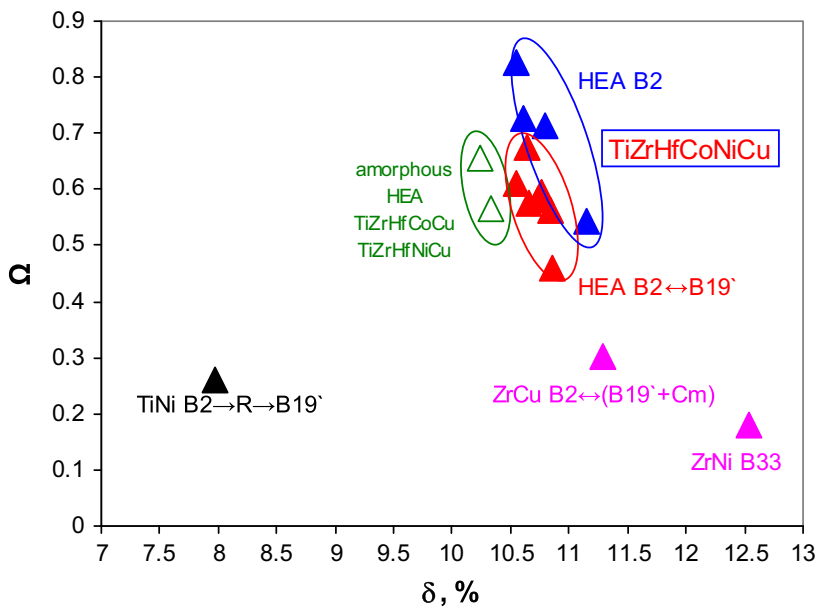

Fig. $6 \Omega$ parameter $\left(\Omega=\frac{T_{\text {mett }} \Delta S_{\text {mix }}}{\left|\Delta H_{\text {mix }}\right|}\right)$ dependence upon atomic size difference $(\delta)$ for TiZrHfCoNiCu high-entropy intermetallics and some amorphous HEAs and binary intermetallic compounds

exist in the very narrow VEC window-7-7.2 electron per atom, while stable B2 phase of this intermetallic family exists in much wider VEC range $6.75 \div 7.25$ electron per atom.

In Fig. 6 , the $\Omega$ parameter $\left(\Omega=\frac{T_{\text {melta }} \Delta S_{\text {mix }}}{\left|\Delta H_{\text {mix }}\right|}\right)$ dependence upon atomic size difference $(\delta)$ can be seen. It is clear that $\Omega$ is below 1, which, according to [42], means that intermetallics or bulk metallic glasses ought to form. It was proved for TiZrHfCoNiCu equiatomic alloy in [15], where (100) superstructural reflection, characteristic for B2 type of ordering, was detected. On the other hand, atomic size difference for intermetallic compounds of TiZrHfCoNiCu family is higher than for amorphous HEA, confirming definite tendency towards sluggish diffusion.

HEAs studied in the present investigation have shown resistance to plastic deformation and diffusion processes 
superior to existing HTSMA due to their intrinsic multicomponent design. So, the directions for HTSMA improvement indeed lead us successfully to the qualitatively novel functional materials-high-entropy shape memory alloys.

\section{Conclusions}

- It can be concluded that existing HTSMAs based upon certain chemical elements still show significant drawbacks mostly related to plastic deformation that accompanies accumulation of the martensitic one and to diffusive processes, taking place in these materials.

- Directions for HTSMA improvement are related mostly to suppression of the plastic deformation through strengthening by substructure refinement, solid solution hardening and prevention of the diffusion processes of internal stresses relaxation and structural fatigue.

- Mutual application of these directions lead to the creation of the novel functional materials, high-entropy shape memory alloys; for them, all those directions are implemented by their multi-component design.

- Martensitic transformation in high-entropy shape memory alloys takes place at elevated temperatures and is accompanied by shape memory behaviour with complete shape recovery (1-2\% of the recovered strain), which favourably distinguishes these novel shape memory materials from the existing high-temperature shape memory alloys.

- There is definite need in extensive experimental (X-ray, TEM, SEM, etc.) and modelling and of the crystal and electronic structure of such materials in order to develop certain models for prediction MT temperatures, mechanical and functional properties' further enhancement, etc.

- On top of the understanding of the physical origin of the phase stability, interatomic interaction and chemical bond in these materials, it is necessary to continue experimental studies of the alloying changes within existing compositions of high-entropy shape memory alloys and additional alloying as well.

- As these materials were studied only in the as-cast conditions, it is necessary to explore the influence of various thermal/mechanical treatments on structural and phase transformations in them.

\section{References}

1. Duerig TW, Melton KN, Wayman CM (1990) Engineering aspects of shape memory alloys. Butterworth-Heinemann Ltd., London
2. Otsuka K, Wayman CM (1998) Shape memory materials. University Press, Cambridge

3. Buehler WJ, Gilfrich JW, Wiley RC (1963) Effect of low-temperature phase changes on the mechanical properties of alloys near composition TiNi. J Appl Phys 34:1475-1477

4. Otsuka K, Ren X (2005) Physical metallurgy of Ti-Ni-based shape memory alloys. Prog Mater Sci 50:511-678

5. Warlimont H, Delaey L (1974) Martensitic transformations in copper-, silver- and gold-based alloys. Pergamon Press, Oxford

6. Kurdyumov GV, Khandros LG (1949) O « термоупругом » равновесии при мартенситных преврашениях (On the "thermoelastic" equilibrium in martensitic transformations). Dokl Akad Nauk SSSR 66(2):211-214 in Russian

7. Miyazaki S, Igo Y, Otsuka K (1986) Effect of thermal cycling on the transformation temperatures of $\mathrm{Ti}-\mathrm{Ni}$ alloys. Acta Metall 34:2045-2051

8. Pelton AR (2011) Nitinol fatigue: a review of microstructures and mechanisms. J Mater Eng Perform 20(4-5):613-617

9. Furuya Y, Park YC (1992) Thermal cyclic deformation and degradation of shape memory effect in Ti-Ni alloy. Nondestruct Test Eval 8-9:541-554

10. Niendorf T, Krooß P, Batyrsina E, Paulsen A, Motemani Y, Ludwig A, Buenconsejo P, Frenzel J, Eggeler G, Maier HJ (2015) Functional and structural fatigue of titanium tantalum high temperature shape memory alloys. Mater Sci Eng A 620:359-366

11. Kumar PK, Lagoudas DC (2010) Experimental and microstructural characterization of simultaneous creep, plasticity and phase transformation in $\mathrm{Ti}_{50} \mathrm{Pd}_{40} \mathrm{Ni}_{10}$ high-temperature shape memory alloy. Acta Mater 58:1618-1628

12. Firstov GS, Van Humbeeck J, Koval YN (2006) High temperature shape memory alloys problems and prospects. J Intel Mater Syst Struct 17:1041-1047

13. Ma J, Karaman I, Noebe RD (2010) High temperature shape memory alloys. Int Mater Rev 55:257-315

14. Firstov G, Koval Y, Van Humbeeck J, Timoshevskii A, Kosorukova T, Verhovlyuk P (2015) Some physical principles of high temperature shape memory alloys design. In: Resnina N, Rubanik V (eds) Shape memory alloys: properties, technologies, opportunities. Trans Tech Publications Inc., Zurich, pp 207-232

15. Firstov GS, Kosorukova TA, Koval YN, Odnosum VV (2015) High entropy shape memory alloys. In: Mater Today: Proceedings (to be published)

16. Firstov GS, Koval YN, Van Humbeeck J, Ochin P (2008) Martensitic transformation and shape memory effect in $\mathrm{Ni}_{3} \mathrm{Ta}$ : a novel high-temperature shape memory alloy. Mater Sci Eng A 481-482:590-593

17. Inorganic Material Database (AtomWork), http://crystdb.nims.go. jp/index_en.html

18. Declairieux C, Denquin A, Ochin P, Portier R, Vermaut P (2011) On the potential of $\mathrm{Ti}_{50} \mathrm{Au}_{50}$ compound as a high temperature shape memory alloy. Intermetallics 19:1461-1465

19. Koval YN (2000) High temperature shape memory effect in some alloys and compounds. Mater Sci Forum 327-328:271-278

20. Otsuka K, Oda K, Ueno Y, Piao M, Ueki T, Horikawa H (1993) The shape memory effect in a $\mathrm{Ti}_{50} \mathrm{Pd}_{50}$ alloy. Scripta Metallurgica et Materiala 29(10):1355-1358

21. Vermaut P, Declairieux C, Ochin P, Kolomytsev V, Pasko A, Monastyrsky G, Denquin A, Portier R (2013) Martensitic transformation and shape memory effect at very high temperatures in HfPd and TiAu intermetallic compounds. J Alloys Compd 577S:S388-S392

22. Koval YN, Firstov GS, Delaey L, Van Humbeeck J, Jang WY (1995) B2 intermetallic compounds of Zr. New class of the shape memory alloys. J Phys IV 5(C8):1103-1108 
23. Kosorukova T, Firstov G, Koval Y, Ivanchenko V, Van Humbeeck J (2013) Phase transformations and shape memory effect in alloys of Zr-Ni-Co system. Mater Sci Forum 738-739:123-127

24. Koval Y, Firstov G, Odnosum V (2013) High temperature martensitic transformation and shape memory behavior in HfIr intermetallic compound. Mater Sci Forum 738-739:72-76

25. Fonda RW, Jones HN, Vandermeer RA (1998) The shape memory effect in equiatomic $\mathrm{TaRu}$ and $\mathrm{NbRu}$ alloys. Scripta Mater 39:1031-1037

26. Yamabe-Mitarai Y, Hara T, Miura S, Hosoda H (2006) Mechanical properties of Ti-50(Pt, Ir) high temperature shape memory alloys. Mater Trans 47:650-657

27. Firstov GS, Koval YN, Van Humbeeck J, Portier R, Vermaut $P$, Ochin P (2006) Phase transformation in $\mathrm{Zr}-29.56$ at.\% $\mathrm{Cu}-19.85$ $\mathrm{Ni}$ at.\% melt-spun high-temperature shape memory alloy. Mater Sci Eng A 438-440:816-820

28. Firstov G, Koval Y, Lotkov A, Grishkov V, Van Humbeeck J (2012) The increase of the martensitic deformation during shape memory effect in deformed TiNi. Funct Mater Lett 5:12500111-1250011-4

29. Sawaguchi T, Sato M, Ishida A (2002) Microstructure and shape memory behavior of $\mathrm{Ti}_{51.2}\left(\mathrm{Pd}_{27.0} \mathrm{Ni}_{21.8}\right)$ and $\mathrm{Ti}_{49.5}\left(\mathrm{Pd}_{28.5} \mathrm{Ni}_{22.0}\right)$ thin films. Mater Sci Eng A 332(1-2):47-55

30. Firstov GS, Van Humbeeck J, Koval YN (2004) Comparison of the high temperature shape memory behaviour for $\mathrm{ZrCu}$-based, Ti-Ni-Zr and Ti-Ni-Hf alloys. Scripta Materialia 50:243-248

31. Firstov GS, Van Humbeeck J, Koval YN (2004) High-temperature shape memory alloys: some recent developments. Mater Sci Eng A 378:2-10

32. Yeh JW, Chen SK, Lin SG, Gan JY, Chin TS, Shun TT, Tsau CH, Chang SY (2004) Nanostructured high entropy alloys with multiple principal elements: novel alloy design concepts and outcomes. Adv Eng Mater 6:299-303
33. Zhang Y, Zuo TT, Nang Z, Cao MC, Dahmen KA, Liaw PK, Lu ZP (2014) Microstructures and properties of high entropy alloys. Prog Mater Sci 61:1-93

34. Murty BS, Yeh J-W, Ranganathan S (2014) High entropy alloys. Elsevier Science \& Technology Butterworth-Heinemann Ltd, Oxford

35. Guo S, Liu CT (2011) Phase stability in high entropy alloys: formation of solid-solution phase or amorphous phase. Prog Nat Sci 21:433-446

36. Firstov SA, Rogul TG, Krapivka NA, Ponomarev SS, Tkach VN, Kovylyaev VV, Gorban' VF, Karpets MV (2014) Solid-solution hardening of a high-entropy AlTiVCrNbMo alloy. Russ Metall (Metally) 4:285-292

37. Tsai KY, Tsai MH, Yeh JW (2013) Sluggish diffusion in Co-CrFe-Mn-Ni high-entropy alloys. Acta Mater 61(13):4887-4897

38. Planes A, Macqueron JL, Ortin J (1988) Energy contributions in the martensitic transformation of shape memory alloys. Philos Mag Lett 57(6):291-298

39. Firstov G, Timoshevskii A, Kosorukova T, Koval Y, Matviychuk Y, Verhovlyuk P (2015) Electronic and crystal structure of the high entropy TiZrHfCoNiCu intermetallics undergoing martensitic transformation, ESOMAT-2015, EDP Sciences, MATEC Web of Conferences, Antwerp (to be published)

40. Koval YN, Firstov GS, Kotko AV (1992) Martensitic transformation and shape memory effect in $\mathrm{ZrCu}$ intermetallic compound. Scripta Metall et Mater 27(12):1611-1616

41. Ma LQ, Wang LM, Zhang T et al (2002) Bulk glass formation of $\mathrm{Ti}-\mathrm{Zr}-\mathrm{Hf}-\mathrm{Cu}-\mathrm{M} \quad(\mathrm{M}=\mathrm{Fe}$ Co, Ni) alloys. Mater Trans 43:277-280

42. Yang X, Zhang Y (2012) Prediction of high-entropy stabilized solid-solution in multi-component alloys. Mater Chem Phys 132:233-238 